\title{
Methods of Assessing the Efficiency of Public Spending on Research and Development Design Work
}

\author{
Irina Evgenyevna llyina
}

Federal State Institution "Russian Scientific Research Institute of Economics, Politics and Law in Science and Technology" Email:skvo_ie@mail.ru

\section{Olga Leonidovna Sergeeva}

Federal State Institution "Russian Scientific Research Institute of Economics, Politics and Law in Science and Technology" Email: sergeeva_ol@riep.ru

\section{Doi:10.5901/mjss.2015.v6n4p250}

\section{Abstract}

The study research is devoted to the analysis of the effectiveness of public spending on scientific research and experimental development (hereinafter $-R \& D$ ), providing intellectual capital growth and the economy reindustrialization. The urgency of this problem is confirmed by the fact that Russia currently holds a leading position in the world for public funding of research and development (70\%), but has a relatively low level of patent activity and imports technology three times more than it exports. Production of the technologies not attractive for business at the expense of the budget is the most important problem hindering enhance of national competitiveness and technological independence, taking into account the current economic and geopolitical challenges. The aims and objectives of the study include following: the development of methodology for assessing the efficiency of public spending on $R \& D$ to address the economic, social problems and problems of state security. The study shows that the efficiency of public spending undertaken by public authorities, as the main managers of budgetary funds can be evaluated and analyzed based on strategic targets, as well as basic and advanced performance indicators of investment in $R$ \& $D$. This assessment will, if necessary, timely adjust the direction of spending in order to achieve maximum cost-effectiveness. We prove that the assessment of the public spending on $R \& D$ effectiveness is an essential element of public administration that provides reindustrialization by creating a critical mass as a fundamentally new technologies and techniques removing import dependence. It has been revealed that the developed method defines a single approach to monitor the effectiveness of the federal executive authorities, aimed at developing an innovative economy that provides a transition to more efficient management models of $R \& D$ investment. Key indicators and the procedure for determining the effectiveness of public financial support for the implementation of research, development and engineering works, and use of $R \& D$ results into economic circulation have also been identified in order to ensure sustainable economic development. It is concluded that the method of evaluating of the public spending on $R \& D$ effectiveness, proposed by the authors, will help to make timely management decisions contributing to the achievement of economic, social problems and problems of state security. In turn, this should facilitate the transition to a new model of innovation development of economy based on the timing of investment flows in research and development, patent activity, as well as the import of technologies, licenses and high-tech products.

Keywords: performance evaluation, public expenditure, research and development design development, knowledge-intensive sectors of the economy, performance indicators.

\section{Literature Review}

The effectiveness of R\&D funding, regardless of its source, is determined by the volume of the results and their practical demand both in Russia and abroad (llyina, 2014). The results of intellectual property (hereinafter - RIA) should contribute to the achievement of the target indicators of the state socio-economic development, and expansion of the global competitive advantage of the Russian economy in the traditional areas (energy, transport, agriculture, processing of natural resources). At the same time institutional conditions and technological groundwork should be created in order to ensure translation of the Russian economy in the mode of innovation development (Concept of long-term socio-economic development of the Russian Federation for the period up to 2020, 2008). Evaluation of scientific organizations effectiveness is based on the analysis and comparison of performance in the following areas: scientific potential and effectiveness research; the involvement of the scientific organization in the national and international research and education community; commercialization and practical value of research results; staffing scientific organization; resource 
security research organization; the state of the financial activities of the scientific organization (Typical performance assessment methodology of scientific organizations carrying out research, development and technological works of civil appointment, approved by order of the Russian Ministry of 05.03.2014 № 161; Rules for assessing and monitoring effectiveness of scientific organizations carrying out research, developmental and technological works of civil appointment, approved by Resolution of the Government of the Russian Federation of 08.04.2009 № 312). American budgeting system operates on the basis of US law "On evaluating the performance of public institutions» (Government Performance Results Act, GPRA, 1993). In accordance with the requirements of GPRA, each agency shall prepare a report on its activities for the previous fiscal year, which shall include a comparison of the achieved results of socioeconomic efficiency and the planned ones. If the actual figures do not correspond to the planned and the stated goals are not met, the agency is required to explain the causes and determine the schedule of events, the implementation of which will reach the planned targets. If the results of the reporting period indicate that the originally selected targets are unattainable, agencies in their reports required to explain why and suggest new wording. Under GPRA, leaders have the right to reallocate resources between different items of expenditure within the budget allocated to them (D.A. Rubvalter, S.S. Shuvalov, 2007). In the UK the effectiveness of public spending on R \& D assessing system is carried out according to the Research Excellence Framework (REF, 2014) and provides the evaluation of the scientific activities of organizations (universities) in the UK, which is carried out in 36 research areas by specialized expert sub-committees under the leadership of four Central Commissions (Panel criteria and working methods. Research Excellence Framework, 2014).

\section{Research Methods}

The functions of the federal executive authorities is to ensure the solution of economic, social problems and problems of state security. One of the main tasks of $R \& D$ investment for the federal authorities is to encourage the development of economic sectors through:

- Ensuring the competitiveness and innovative development of economic sectors (short-term goal);

- The creation of new knowledge-intensive industries with export potential (medium-term objective);

- $\quad$ Forming the groundwork for long-term development of the economy (long term goal).

1. Ensuring competitiveness and innovative industries, contributing significantly to the gross domestic product, at the expense of creating a pool of technology is ready for practical application at the same time urge economic entities to use these technologies through incentive regulation - the adoption of new standards (the "pulling" standardization) by setting requirements for product quality and environmental requirements for production. It is necessary to estimate the amount of RIA in technology and patents at the same time with the creation of a pool of technologies necessary in order to protect the domestic market from the entry of foreign competitors and to access the foreign markets. Cost-effectiveness of $R$ \& $\mathrm{D}$ depends on the measures taken by the federal authorities as an investor in the process of stimulating the introduction and use of technology. For military guarded the RIA criterion cannot be applied, since this information may relate to the state or commercial secret. Evaluating the effectiveness of the practical application of technology ( $R$ \& $D$ involvement in economic circulation) is carried out in two directions:

- If the technology is focused on the industry, where the state has a monopoly, the performance indicators relate to the number of actors (state monopoly, state-owned companies), the technology and the economic impact of the use of technology (production volume obtained with the use of new technologies, reduction of costs environmental remediation (restoration) resulting from the application of new technologies, reduction of consumption of resources; the share of high-tech jobs in total jobs in the industry);

- If the technology is used in the free market, the efficiency should be judged by the number of subjects using new high technology and the share of high-tech jobs in total jobs in the industry.

2. The creation of new knowledge-based industries with export potential, involves the formation of infrastructure for new businesses and the creation of a pool of technologies that are the basis for the design of future economic sectors. The effectiveness of the federal authorities is estimated by the number of new businesses created (innovative SME), subjects carried out a full re-engineering of production (services), the share of exports of technology (license), as well as the number of transitions from the innovative SME to medium and large business.

3. Formation of the groundwork for long-term development of the economy is based on the fundamental and exploratory research. This goal is aimed at ensuring the popularization of science and technology to attract young people to science, the intellectual capital of the nation's competitiveness at international 
level. The main indicators that indicate the efficiency of investment in $R$ \& $D$ are the number of publications in academic journals indexed by the WOS, Scopus, ERIH databases; the number of the "high-end modules" program students; number and volume of load, creates a unique scientific installations and centers for collective use (CCU); the number of young researchers recruited.

Formation of the groundwork for long-term development of the economy provides the basis for the creation of new knowledge-based industries with export potential, which later can transform into a competitive and innovative industry that will attract extra investment.

The solution of social problems of the state is achieved through the state order to guarantee the stability of innovative companies through a new business standards to ensure 'repression' is not innovative market participants. State order is "a powerful tool" solutions to social problems and to stimulate economic development.

National security and technological independence are carried out through the state order to guarantee the RIA developing military enterprises economic stability. Mode state secret military technology should not be an obstacle to the introduction into circulation of the RID, which do not provide key advantages in the field of national security and performance characteristics.

To address the social, economic problems and problems of national security the state creates a list of scientific development directions priority, approved by the presidential decree, on the basis of which the established procedure of the R \& D public funding shall be approved. Implementation of the state program is carried out by the appropriate federal authorities on the basis of the budgetary appropriations allocated from the budget of the Russian Federation.

- The state reduces the risks by means of financing of the $R \& D$ costs, sharing responsibility with the business, thereby increasing the attractiveness of the industry and interest in achieving results, providing a profit. The work of financial and institutional mechanisms of the state to reduce the risk of business should strive to achieve a balance of co-financing:

- In a high risk knowledge-intensive industries $70 \%$ is carried by the state and $30 \%$ - by business;

- In innovative sectors 30\% the state participation share comes to 30\% and the business participation share amounts $70 \%$.

The quest for such a relation can provide the best possible interaction between government and business in the development of innovative economy.

To achieve these goals Federal executive bodies (FEB) organizes consortia and ensures involvement of previously created RIA into the economy, creates a pool of industrial partners engaged in financial and organizational participation in $R \& D$.

Cost-effectiveness of a particular FEB on $R$ \& $D$ is estimated by comparing the integral increment cost effectiveness of all FEB on research and development in the assessed year compared with the previous year and growth in the volume of its $R \& D$ budget financing for the period. Such an approach eliminates the differences in the specific activities of federal executive bodies and ensures the continuity of the state policy on development of economic sectors, as well as the corresponding software-target approach the state.

\section{The Result of the Analysis}

Typical methods of evaluating the effectiveness of public spending on $R \& D$.

$R \& D$ can be considered as an instrument for solving the economic problems of the state in the short, medium and long term. In the short term the activities of FEB should be aimed at ensuring the competitiveness and innovative development of existing industries. In the medium term it should be aimed at the creation of new high-tech industries with export potential. It's goal in the long-term perspective is forming the groundwork for long-term economic development.

Evaluating the effectiveness of public spending on $R \& D$ is performed by comparing the amount of integral indicators of growth performance cost of all federal executive bodies on research and development in the assessed year compared with the previous year and growth in budget funding of $R \& D$ for the corresponding period in general.

Performance Indicators for each FEB can be divided into basic and optional. The basic indicators of performance refers to indicators related to the achievement of one of the three objectives (ensuring global competitiveness and innovative development of the industry, the creation of new knowledge-based industries with export potential, forming the groundwork for long-term development of the economy), which is for the main federal authorities (Table 1). All other indicators in the Table 1 are optional and are taken into account using a discount factor of 0.3 . 
Table 1. Indicators used to assess the effectiveness of public spending on $R \& D$

\begin{tabular}{|c|c|c|}
\hline Goal & \multicolumn{2}{|c|}{ Indicators } \\
\hline \multirow{18}{*}{$\begin{array}{l}\text { A. Ensuring Global Competitiveness } \\
\text { and innovative sectors development }\end{array}$} & $\mathrm{A}_{1}$ & Number of the RIA established \\
\hline & $\mathrm{A}_{2}$ & Number of the RIA used, created without the FEB participation \\
\hline & $\mathrm{A}_{3}$ & Number of the RIA used, created with the FEB participation \\
\hline & $\mathrm{A}_{4}$ & Number of the RIA created, being secured in RF \\
\hline & $A_{5}$ & Number of the RIA created, being secured outside RF \\
\hline & $A_{6}$ & Number of prototypes \\
\hline & $A_{7}$ & Number of licenses allowing the use of the technologies \\
\hline & $A_{8}$ & Licenses export volume \\
\hline & $\mathrm{A}_{9}$ & Volume of innovative (high-tech) products \\
\hline & $\mathrm{A}_{10}$ & Volume of high-tech products exports \\
\hline & $\mathrm{A}_{11}$ & Number of technologies for efficient use of natural resources \\
\hline & $\mathrm{A}_{12}$ & Share of high-tech jobs in the total number of jobs \\
\hline & $\mathrm{A}_{13}$ & Number of technologies that protect and restore the environment \\
\hline & $\mathrm{A}_{14}$ & Revenues from the sale of high-tech output per worker \\
\hline & $\mathrm{S}_{1}$ & Number of the "pulling" standards used by business entities \\
\hline & $\mathrm{S}_{2}$ & Amount of the state order guaranteed, based on the use of new technologies \\
\hline & $\mathrm{R}_{0}$ & $\begin{array}{l}\text { Deviation from the established ratio R \& D expenditures to income payments to the budget } \\
\text { from the sale of high-tech products }\end{array}$ \\
\hline & $\mathrm{R}_{1}$ & Set ratio of budgetary and extra-budgetary funding for the purpose of $A(1: 3)$. \\
\hline \multirow[t]{5}{*}{$\begin{array}{l}\text { B. The creation of new knowledge- } \\
\text { based industries with export potential }\end{array}$} & $\mathrm{B}_{1}$ & $\begin{array}{l}\text { Number of new subjects of innovative entrepreneurship, including small ones (innovative } \\
\text { SME) }\end{array}$ \\
\hline & $\mathrm{B}_{2}$ & Number of subjects, having reengineered or created a new industry \\
\hline & $\mathrm{B}_{3}$ & Number of enterprises "translated" from small to medium-sized \\
\hline & $\mathrm{B}_{4}$ & Number of enterprises "translated" from medium-sized small to big \\
\hline & $\mathrm{R}_{2}$ & Set ratio of budgetary and extra-budgetary funding for the purpose of $B(3: 1)$. \\
\hline \multirow{8}{*}{$\begin{array}{l}\text { C. Formation of the groundwork for } \\
\text { long-term economic development }\end{array}$} & $\mathrm{C}_{1}$ & Number of publications in international scientific journals \\
\hline & $\mathrm{C}_{2}$ & Proportion of young researchers in the total number of researchers \\
\hline & $\mathrm{C}_{3}$ & Number of students on programs including "high-end" modules \\
\hline & $\mathrm{C}_{4}$ & Cost of equipment CCU \\
\hline & $\mathrm{C}_{5}$ & Cost of unique scientific installations \\
\hline & $\mathrm{C}_{6}$ & Loading capacity infrastructure (USP, CCU) \\
\hline & $\mathrm{C}_{7}$ & Cost of information provision \\
\hline & $\mathrm{C}_{8}$ & Number of references to information resources and databases \\
\hline
\end{tabular}

$A, B, C$-- the basic indicators for the goals $A, B, C$ respectively;

$\mathrm{R}$ - indicators used to calculate the deviation from the established target values

$\mathrm{S}$ - indicators to assess the accompanying measures to promote the use of the $R$ \& $D$ results

1. Assessment of the R \& D cost-effectiveness of the s-th FEB:

$\{$ The FEB is effective, if Es $>$ Ps

\{ The FEB is ineffective, if Es $\leq$ Ps ' where:

Es - growth rate of $R$ \& $D$ performance of the s-th FEB;

$P s$ - growth rate in budget funding of $R \& D$ by the s-th FEB

Growth rate of $R \& D$ performance of the s-th FEB:

$$
E s=D s+\sum_{i=1}^{n} \frac{K_{s i}^{T}}{K_{s i}^{T-1}}+0.3 \sum_{i=1}^{m} \frac{L_{s i}^{T}}{L_{s i}^{T-1}}
$$

where:

Ds - the indicator of the s - th's FEB achievement of set values to attract extra budgetary funds (EBF)for R \& D

$K_{s i}^{T}$ - the value of a key indicator of the impact of $s$ - th FEB in the estimated year (table 1); $K_{s i}^{T-1}-$

the value of the main indicators of the $s$ - th FEB in the previous year prior ro being estimated (table 1); 
$L_{s j}^{T}$ - the value of additional indicators of s-th FEB in the estimated year (table 1);

$L_{s j}^{T-1}$ - the value of additional indicators of the s-th FEB in the year prior to being evaluated (table 1);

0.3 - reduction factor applied on the basis of peer review, additional performance indicators.

The basic variables are indicators (Table 1), letter indices in which coincide with the designation of the main objectives of FEB. All other parameters listed in Table 1 are optional.

The Indicator of the s-th's FEB achievement of set values to attract extra-budgetary funds for R \& D:

where:

$$
\mathrm{Ds}=\frac{W s}{W},
$$

Ws - EBF share in the total R \& $D$ funding with the participation of the $\mathrm{s}-$ th FEB in the estimated year, \%; $W$ - set value share of EBF in total $R$ \& $D$ funding with $F E B, \%$.

$\mathrm{SW}=70 \%$ for the A goal

$\{\mathrm{W}=30 \%$ for the $\mathrm{B}$ goal

Rate of changes in budget funding of $R \& D$ by the s-th FEB:

$$
P S=\frac{V_{S}^{T}}{V_{S}^{T-1}} \text {, }
$$

where:

$V_{S}^{T}$ - amount of the budget funding of R \& $\mathrm{D}$ by the s-th FEB in the estimated year;

$V_{S}^{T-1}$ - amount of the budget funding of R \& $\mathrm{D}$ by the s-th FEB in the pre-estimated year.

\section{Evaluating the effectiveness of public spending on $R$ \& $D$}

$\left\{\begin{array}{c}\text { Public exenditure on R } D \text { are effective if } \sum_{s=1}^{b} E_{S}>\sum_{s=1}^{b} P_{S} \\ \text { Public expenditure on R } D \text { are ineffective if } \sum_{s=1}^{b} E_{S} \leq \sum_{s=1}^{b} P_{S}\end{array}\right.$.

\section{Discussion}

The main task of the FEB in the short term is to create a pool of technology ready for practical application. The effectiveness of $R \& D$ expenditure is directly dependent on the measures taken by the FEB as an investor / regulator to promote the introduction and use of technology. While a pool of technologies is being created it is necessary to evaluate the RIA within the technologies in order to protect the domestic market from the entry of foreign competitors and to access foreign markets. For the military guarded RIA such criterion cannot be used because the information contained in these RIA may refer to state secrets. Evaluating the effectiveness of the practical application of technologies is carried out according to the industries in which technology is used:

- If the technology is focused on the industry, where the state has a monopoly, the performance indicators will be following: the number of actors (state monopoly, state-owned companies), using technology and economic benefit from the use of technology (volume production of new products, environmental protection, resource conservation, reduced labor costs);

- If the technology is used in the free market, the efficiency should be judged by the number of subjects using the technology and created high-tech jobs.

In the medium term, the FEB should focus on the creation of infrastructure for the development of new high-tech industries and in the long term it should focus on formation of fundamental groundwork for the development not only of new industries, but also the knowledge economy. An important point in the present scheme is the process of co-financing the government and business $R \& D$. Financing of the costs of $R \& D$ increases the attractiveness of the industry state for business, thereby reducing risks and sharing responsibility with the business. For the business co-financed $R \& D$ expenditures leads to interest in these activities. However, the percentage of the cost of government and business should be different. In the short term, this ratio should approach $30 \%$ of state participation and $70 \%$ of business participation; in the medium: $70 \%$ of the state and $30 \%$ of business; in long-term funding for basic research is carried out mainly by the state. The quest for such a relation can provide the best possible interaction between government and business in the development of innovative economy.

Economic development through the practical use of RIA and indirectly stimulates the solution of social problems and problems of state security. Such stimulation can be performed in two ways:

- Firstly, by placing the state order for research and development in the health sector, the production of pharmaceuticals, construction of social objects and others. And the state defense order for research and 
development of military, special and dual purpose;

- Secondly, by translation of the technologies and developments not directly providing the key benefits of arms and military equipment to the civil sphere.

\section{References}

\section{Normative Legal Acts}

Order of the Government of the Russian Federation of 17.11.2008, № 1662-r "On the Concept of long-term socio-economic development of the Russian Federation for the period up to 2020".

Order of the Russian Ministry of 02.02.2015, № 40 "On Approval of Procedures for assessing the effectiveness of activities of scientific organizations under the Ministry of Education and Science, performing research, development and engineering works for civil use".

Order of the Ministry of Finance of Russia from 07.26.2013, № 75n "On approval of the methodology for assessing progress subjects of the Russian Federation in the field of improving the efficiency of budget spending, and the dynamics of these results".

\section{Literature}

Burutin, A.G. (2013). Problems of the state strategic planning theory and practice in the Russian Federation: a conceptual vision. State Government and local government, №4, 3 - 6.

Edkova, T.A.; Kalmikova, A.V.; Krysenkova, N.B. etc. (2014) Industrial parks in the infrastructure of innovative development: a monograph. (Ed. by Tereshchenko, L.K). Moscow: INFRA-M, 245.

Gubin, E.P. (2015). Government and business in a legal reform. Journal of Russian law, №1, 23 - 30.

Golubtsov, V.G. (2014). Improving the legal regulation of relations in the field of public-private partnerships at the present stage. Bulletin of Perm University. Jurisprudence, №1, 179 - 188.

Ivanov, J.E. (2013) Foreign experience of innovative development of small business. Young scientist, №12, 306-308.

Ilyina, I.E. (2014) The new model of grant financing of Russian science. In prof. A.V. Babkin (Ed.). Innovative economy and industrial policy in the region -- EcoProm 2014 (pp. 39-45). Saint-Petersburg: Publishing House of the Polytechnic University.

Kalyatin, V.O.; Naumov, V.B.; Nikiforov, T.S. (2011) European, American and indiam experience in the sphere of public support of innovation. Russian Law Journal. № 1, 171 - 183.

Research Excellence Framework 2014. Panel criteria and working methods. [Online] Available: http://www.ref.ac.uk/pubs/2012-01 (September, 10, 2014).

Research Excellence Framework 2014. Panel criteria and working methods. [Online] Available: http://www.ref.ac.uk/pubs/2012-01 (September, 10, 2014).

Rubvalter, D.A.; Shuvalov, S.S. (2007). The leading foreign countries experience in the field of state regulation of research and development. Information-analytical bulletin №1 of the Center for Science Research and Statistics, a series of "Analysis and use of foreign experience". Moscow.

Startsun, V.N. (2014) The participation of military organizations in civil matters. The electronic scientific edition "Martial law", №1. [Online] Available: www.voennoepravo.ru/files/Starzun.doc. 